\title{
Seeing is better than believing: visualization of membrane transport in plants Markus Geisler
}

\begin{abstract}
Recently, the plant transport field has shifted their research focus toward a more integrative investigation of transport networks thought to provide the basis for long-range transport routes. Substantial progress was provided by of a series of elegant techniques that allow for a visualization or prediction of substrate movements in plant tissues in contrast to established quantitative methods offering low spatial resolution. These methods are critically evaluated in respect to their spatiotemporal resolution, invasiveness, dynamics and overall quality. Current limitations of transport route predictions-based on transporter locations and transport modeling are addressed. Finally, the potential of new tools that have not yet been fully implemented into plant research is indicated.
\end{abstract}

\author{
Address \\ University of Fribourg, Department of Biology, Chemin du Musée 10, \\ $\mathrm{CH}-1700$ Fribourg, Switzerland
}

Corresponding author: Geisler, Markus (markus.geisler@unifr.ch)

\section{Introduction}

Because you have seen me, you have believed; blessed are those who have not seen and yet have believed. ${ }^{1}$

John 20: 29

The catalyzed movement of substrates across membranes, commonly referred to as transmembrane transport, has always been a hotspot in plant biology [1]. Throughout

\footnotetext{
${ }^{1}$ Please note that this bible citation is not at all meant as a religious statement but a stylistic element acknowledging the effort of the transport field to promote techniques allowing for a quantitative visualization of transport, which is the content of this review.
}

the 80 s and 90 s, the plant transport community concentrated mainly on biochemical characterization of single transporter isoforms with a focus on a kinetic level (the 'queen of transport experiments' [2]). In the last two decades, deep insights into transporter expression, trafficking, regulation and their role in plant physiology were provided. Recently, plant scientists have shifted their interest toward a more integrative investigation of long-range transport routes or transport networks [3-5] that is of water, nutrients or some hormones (for an overview, see Figure 1).

Transport was classically quantified on a whole organ or plant level using radiotracers, external microelectrodes or cell-type specific analyses of transport substrates (for reviews on these methods, see Ref. [6]). While these techniques allow for a high level of temporal resolution, they are limited in the spatial aspect. Therefore, direct and indirect techniques have been developed in order to image either local substrate concentrations or intra and intercellular transport in planta. Here, we present current methods that allow for a quantitative visualization of transmembrane transport and compare them with classical transport measurements and in silico techniques.

\section{Inference of transport routes by transporter imaging}

For several substrates, putative transport routes have been deduced from polar transporter localizations [3,5,7-10]. These cell-biological approaches have been partially backed up by analyses of reporter expression and transport modeling (see below).

The best-understood example is probably the polar transport of the auxin, indole-3-acetic acid (IAA), in the Arabidopsis root tip provided by a network of plasma membrane localized im- and exporters of the ABCB, AUX1/LAX and PIN-FORMED (PIN) families [3,11]. Different degrees of tissue-specific and polar locations of members of these families have been established by immunolocalization and fluorescent protein fusions (see Figure 3 ) that are in line with current models of a reversed fountain auxin flux pattern (see Figure 1; [8]). Similarly, the boric acid channel, NIP5;1, and the boron exporter, BOR1, have been localized in a polar fashion in the plasma membranes facing toward soil and stele, respectively, and are therefore suspected to function in the uptake and translocation of boron to support growth of various plant species (see Figure 1; [7]). Likewise, the ABCG-type SL transporter, PDR1, exhibits an asymmetrical localization in the plasma membrane of petunia root 


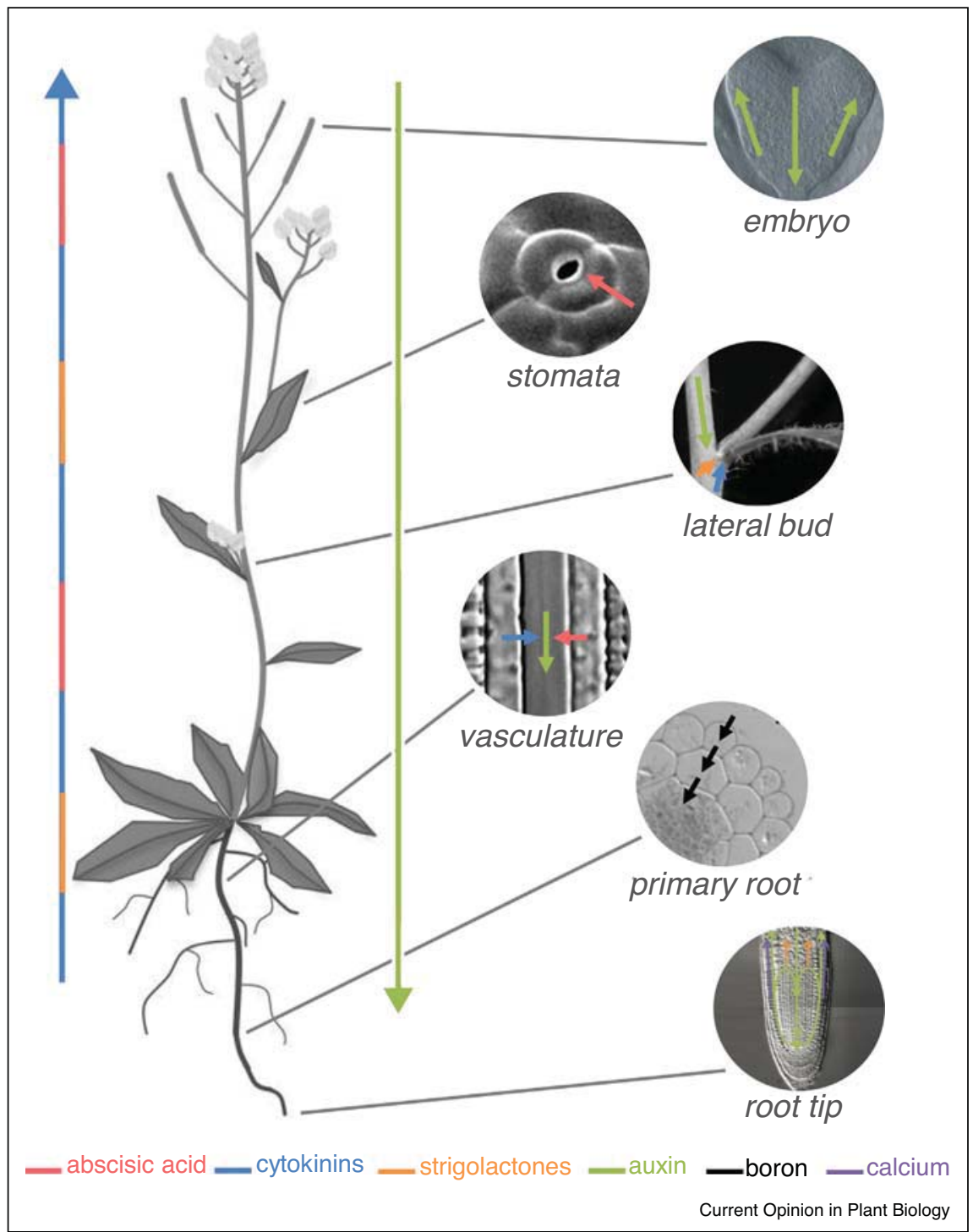

Illustration of trans-membrane, long-range transport routes in plants.

Exemplary long-range transport routes of indicated phytohormones, boron and calcium are indicated by arrows. Note that only long-distance signaling of $\mathrm{Ca}^{2+}$ where it acts as a second messenger but not as a nutrient is indicated. In contrast, boron paths are indicating nutrition routes. Overall figure outline is based on [5]; usage of Arabidopsis model was granted by Mary Lou Guerinot.

tips indicating a directional cell-to-cell transport process at least in this region of the root (see Figure 1; [5]). However, presence of a transporter on a cellular subdomain does not automatically reflect local activity levels. Moreover, this approach failed so far in the prediction of transport routes for non-polar transporters known to be involved in long-distance transport [12].

\section{Quantification of transporter activity or regulation}

A better proxy might be the recently developed transport activity sensors, such as AmTrac and Mep'Trac [13,14], NiTrac1 and PepTrac [15]. Although these transport activity sensors do not strictly monitor transport, and have not yet been tested in planta, they will most likely become valuable, especially in the context of analytes for which no tracers exist.

An alternative approach might be imaging transporter regulation, such as by protein phosphorylation [16]. AGC kinases were shown to phosphorylate and thus alter transport activities of auxin transporters of the PIN and ABCB families [16-20], but have not yet been imaged in planta. A future alternative might be offered by novel GFP-based kinase reporters, called SPARK (Separation of Phases-based Activity Reporter of Kinase). SPARK 
offers imaging of fast kinase kinetics and is reversible $\left[21^{\bullet \bullet}\right]$ but has not yet been adapted to plant systems.

\section{Visualization of transporter substrates: in vivo biochemistry}

While some transporter substrates (like some secondary metabolites) are by nature fluorescent and can be followed directly, most are not and thus need either be applied as a radiolabeled or fluorescent version (see below) or require an indicating tool [22]. In vivo biochemistry [23] has provided us with a series of cell-biological techniques that allow for an imaging of either local substrate concentrations or intra and intercellular transport in planta (see Figure 2). However, it is important to keep in mind that most of these techniques indicate local substrate concentrations that are then used as a proxy for transport.

\section{Chemical indicators}

Chemical indicators are fluorescent molecules that respond to the binding of substrates by changing their fluorescence properties ([24]; see Figure 2). They exist for different metal cations (such as zinc, potassium, sodium, magnesium, calcium), protons and chloride and their loading and membrane targeting has been optimized by generating hydrophobic versions that are cytoplasmically cleaved and activated. In plants, the most commonly used $\mathrm{pH}$-indicator and calcium-indicator are BCECF (2',7'-bis-(2-carboxyethyl)-5-(and -6)-carboxyfluorescein) [25] and Fura-2/Calcium Green variants, respectively [24]. The latter can be either non-ratiometric (such as Calcium Green) or ratiometric (Fura-2), allowing one to correct for unequal dye loading, photo-bleaching or focal plane shifts. However, a common problem with chemical indicators in plant cells is that dye loading is hindered by the cell wall or compartmentalization in organelles (mainly vacuoles) avoiding an equal distribution [22,26].

Therefore, genetically encoded (GE) indicators, reporters and sensors [27-30] have been developed that indirectly or directly indicate local substrate concentrations, respectively (Figure 2). They allow for selective targeting to subcellular compartments (by insertion of signal sequences) or to cell types (by choice of promoters) [31].

\section{Reporters}

Expression-based (or signaling) reporters consist of natural or synthetic promoters fused to a reporter gene. Many but not all plant hormones, including auxin, ABA, cytokinin (CK), ethylen, jasmonic acid (JA) and salicylic acid can be visualized in this manner (for reviews, see Refs. $[23,27,30-32])$. Since publication of the prototype artificial auxin-responsive element, DR5 [33], several variants have been developed (for a review, see Ref. [22]). DR5 activation is slow (ca. 2 hour) and reflects an auxin

Figure 2

\begin{tabular}{|c|c|c|c|c|c|c|}
\hline & $\begin{array}{l}\text { Chemical } \\
\text { Indicator }\end{array}$ & Reporter & Sensor & $\begin{array}{l}\text { Fluorescent } \\
\text { substrate }\end{array}$ & $\begin{array}{l}\text { Click- } \\
\text { chemistry }\end{array}$ & $\begin{array}{l}\text { Imaging of } \\
\text { radioactivity }\end{array}$ \\
\hline \multicolumn{7}{|l|}{ Principle } \\
\hline Readout type & $\begin{array}{l}\text { Change of } \\
\text { fluorescent } \\
\text { properties }\end{array}$ & $\begin{array}{l}\text { Promoter } \\
\text { activation, } \\
\text { reporter } \\
\text { degradation }\end{array}$ & $\begin{array}{l}\text { FRET, } \\
\text { change of } \\
\text { fluorescence } \\
\text { intensity }\end{array}$ & Fluorescence & Fluorescence & $\begin{array}{l}\text { (Digital) } \\
\text { Radiography, } \\
\text { Micro- } \\
\text { autoradiography }\end{array}$ \\
\hline Dynamic readout & + & $+/-1$ & + & + & $(+)$ & - \\
\hline $\begin{array}{l}\text { Subcellular } \\
\text { resolution }\end{array}$ & $+/-$ & - & $(+)$ & + & + & $+/-$ \\
\hline Calibration & $+/-$ & $+/-1$ & + & - & - & - \\
\hline \multirow[t]{2}{*}{ Noninvasive } & + & $(+)^{2}$ & $(+)^{2}$ & + & - & - \\
\hline & & & & & \multicolumn{2}{|c|}{ Current Opinion in Plant Biology } \\
\hline
\end{tabular}

Comparison of methods used to derive transmembrane, long-range transport in plants.

Indicated approaches are evaluated with respect to their readout type and dynamic range, their invasiveness, their offered subcellular resolution and their correlation between the amount of detected target molecule and readout (calibration). Target molecules are in blue; fluorescent proteins are depicted as rounded rectangles. Note that principles are illustrative examples and might be not complete; brackets indicate limitations of methods. Figure outline is inspired by Ref. [27]. ${ }^{1}$ Dynamic range and calibration varies between reporter types; ${ }^{2}$ Reporter and sensors require genetic access and are thus not suitable for non-model plants (for details, see text). 


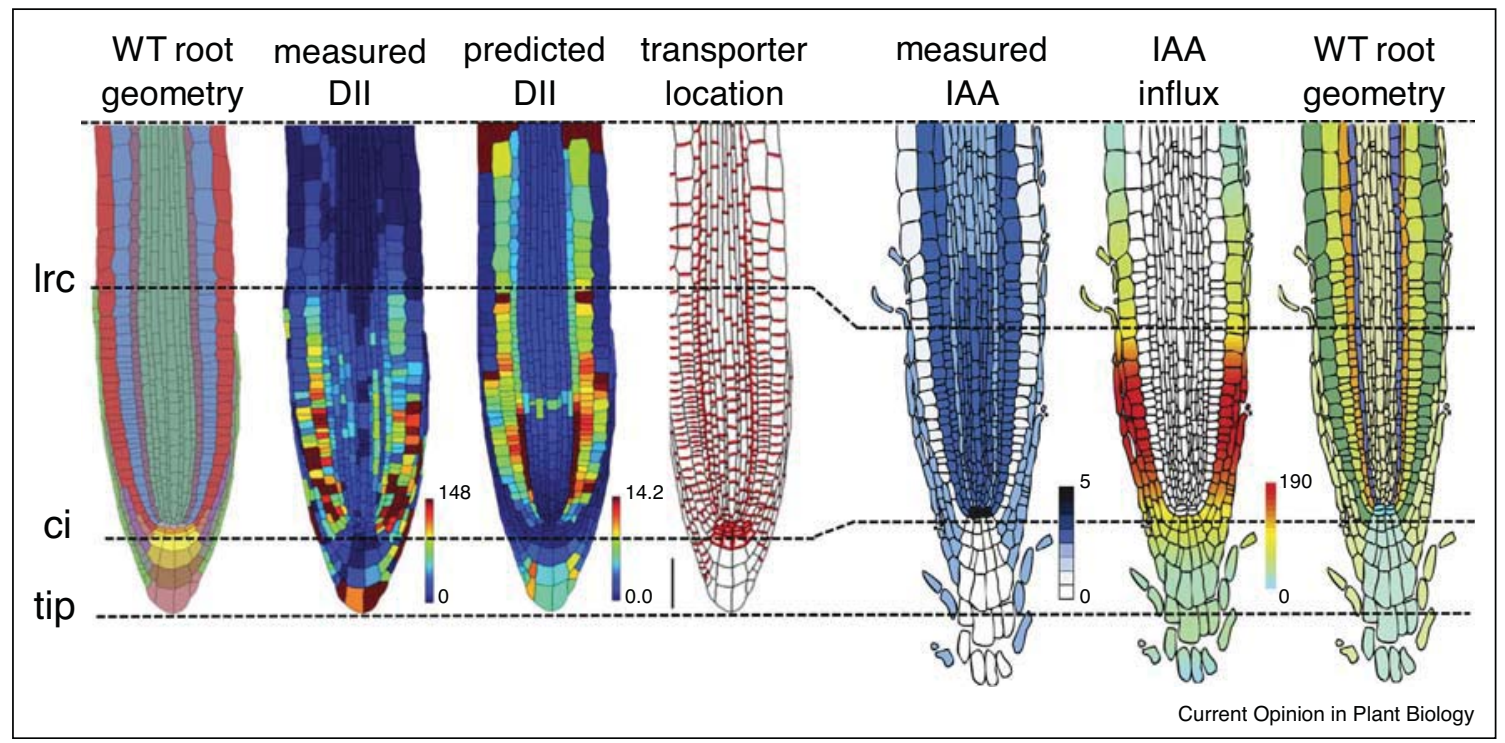

Comparison of imaged, modeled and measured auxin transport in the root tip.

Measured DII-VENUS signals and transporter locations (here: PINs) were extracted from confocal images and are compared with modeled DIIVENUS distribution and predicted auxin fluxes (all taken from Ref. [89']). As reference, imaged auxin (transporter) distributions are compared with heat map presentation of IAA influx profiles measured using an IAA-specific microelectrode [97] or of high-resolution IAA contents measured by MS after cell-type sorting [97,98]. Note that the latter two quantitative transport techniques are not described in this review. Cell types labeled on the schematics of wild-type root geometry (left and right) are given; for identity refer to Refs. [89'] and [97]. Note that the alignment of schematics is based on position of root tips, columella initials (ci) and end of lateral root caps (Irc).

response maximum, and is thus mainly suitable for the root tip $\left[22,34^{\bullet \bullet}, 35\right]$.

Reporters-based on the principle of SCF-mediated proteasomal degradation of transcriptional repressors in the signaling pathway of several hormones were developed increasing the temporal (but also spatial) resolution of expression-based reporters. The blueprint consisted of the DII degron sequence of Aux/IAA repressor proteins of auxin signaling, which was fused to a nuclear targeted VENUS [36]. This module provides a decrease of DIIVENUS reporter fluorescence in tens of minutes upon auxin perception and is therefore suitable to image unequal auxin distribution in bending roots [36]. Combining the degron motive fusion with an auxin-insensitive reporter gene resulted in ratiometric reporters. For example, R2D2, now offers semi-quantitative auxin imaging at very reasonable spatio-temporal resolution $\left[37^{\bullet}, 38,39^{\bullet \bullet}\right]$. Degradation-based reporters have also been developed for GA (GFP-RGA; [40]), JA (Jas9-VENUS; [41]) and SL (StrigoQuant; [42]).

Despite tremendous improvements in expression and degradation-based reporters with respect to speed and sensitivity, their indirect mode of action allows only for at best - semi-quantitative in vivo imaging of local substrate concentrations. Further, reporters display final outputs that integrate over transport, biosynthesis and metabolism. An even more limiting aspect is that their sensitivity is primarily determined by the expression of the employed signaling machinery and thus cell and tissue-specific $\left[34^{\bullet \bullet}\right]$.

\section{Sensors}

A series of genetically encoded activity sensors that are able to report directly and within seconds changes in calcium, proton, energy metabolite, heavy metal or macronutrient concentrations have been established [27,31]. Like reporters, sensor are used to assess resident substrate concentrations that are then often equalized as transport activities [27,43].

The photoprotein aequorin, from jellyfish has been widely used in plants for more than two decades in order to study calcium dynamics by means of emitted bioluminescence [44]. However, due to its low cellular sensitivity, aequorin was slowly replaced by FRET-based sensors (Figure 2; [45]), such as Cameleon [24]. Versions of Cameleon with improved calcium binding affinity and dynamic range [23,27,28] (YC3-60, [46] and YC-nano), were recently used for demonstrating long-range calcium signaling in the root and between shoot and root, respectively [47-49]. The intensiometric calcium sensor, RGECO1, exhibits an increased $(>10 \times)$ sensitivity compared with YC3.6 in response to elicitors of the innate immune response to pathogens, flagelin22 and chitin $\left[50^{\bullet \bullet}\right]$, and R- was used to image auxin-induced calcium 
gradients in root-hair tips and long-distance calcium waves between root cells $\left[51^{\bullet \bullet}\right]$.

For local $\mathrm{pH}$ measurements, single fluorescent protein sensors, such as pHluorins [52], using the $\mathrm{pH}$ sensitivity of EGFP are mainly employed [53 ${ }^{\circ}$. The $\mathrm{pH}$ sensor, pHusion, allows for a ratiometric quantification of cytoplasmic and apoplastic pH [28]. Recently, a pHusion variant allowed measuring $\mathrm{pH}$ in and outside of the TGN/early endosome network demonstrated the role of the V-ATPase for protein secretion $\left[54^{\bullet \bullet}\right]$.

The Frommer group was driving forward the development of FRET sensors for of a wide range of sugars $[23,27,31]$. Beside a quantification of intracellular concentrations, these sensors also permitted the kinetic characterization of individual sugar transporters [1] and the identification of novel transporters [55]. Sensors for transport of ATP; [56,57], ROS, heavy metals (eCALWY) (for references, see Refs. [27,31]) and different macronutrients have been developed (for a review, see Ref. [58]). Very recently, ATP sensing in living plant cells using the FRET-based sensor, ATeam1.03-nD/nA [56], revealed concentration gradients in plant tissues and stress-related dynamics of energy physiology [57].

Hormone imaging by sensors has been achieved first for ABA: two independent groups have developed sensors consisting of a FRET pair that is linked by an ABAresponsive sensory module, called ABACUS [59 ${ }^{\circ}$ ] and ABAleon $\left[60^{\circ}\right.$ ], respectively. Both sensors have proven to be useful in demonstrating kinetics of $\mathrm{ABA}$ transport and dynamics upon application of external ABA, [30,32,59 $\left.{ }^{\circ}\right]$. The nuclear localized GA sensor, GIBBERELLIN PERCEPTION SENSOR 1 (GPS1), allowed sensing of nanomolar concentrations in Arabidopsis [61].

The intensiometric calcium sensor, R-GECO1, was shown to exhibit an increased $(>10 \times)$ sensitivity compared with classical YC3.6 in response to elicitors of the innate immune response to pathogens, flagelin22 and chitin [50 ${ }^{\bullet}$ ]. R-GECO1 was used to image auxin-induced calcium gradients in root-hair tips but also long-distance calcium waves between root cells $\left[51^{\bullet \bullet}\right]$.

\section{Fluorescently labelled substrates}

Fluorescently labeled substrates have only recently been used in plants (Figure 2). The fluorescent BR analog, Alexa Fluor 647-castasterone (AFCS) [62], GA-fluorescein [63] and different fluorescent auxins [34 $\left.{ }^{\bullet \bullet}, 35,64\right]$ have been developed. Moreover, a quantum dot-based fluorescent probe, CdTe-JA, was employed to label JA binding sites in tissue sections of mung bean and Arabidopsis seedlings [65]. Recently, different fluorescent SL analogs were successfully designed: while EGO10A-BP and CISA-1 [66] are constitutively fluorescent variant making it first choice for transport studies,
Yoshimulactone Green or GC242 were constructed to exhibit only fluorescent after cleavage by the SL receptor [67].

Bioactive auxin derivates tagged with fluorescein (IAAFITC) or rhodamine (IAA-RITC) are distributed symplasticly and apoplasticly, respectively [35]. Hayashi et al. designed fluorescent auxin analogs to be actively transported but to be inactive for auxin signaling [34 ${ }^{\bullet \bullet}$ ], while very recently new fluorescently labeled auxins exhibit an anti-auxin activity [64]. The former is important because auxin signaling is known to influence auxin transporter expression and location [34 ${ }^{\bullet \bullet}$ ]. NBD-IAA (7-nitro-2,1,3benzoxadiazole-IAA) revealed a similar auxin distribution as found with DII-based reporters [34 $4^{\bullet \bullet}$ ] but lacked signals in the quiescent center known to be mainly produced by auxin biosynthesis and not transport. A limitation of NBD-auxins is that they are for unknown reasons only working in root and not in shoots [34 $\left.4^{\bullet \bullet}\right]$. Recently, NBD-NAA, whose nuclear import is restricted, was used as a tool to dissect cytoplasmic and ER delivery of nuclear auxin concentrations [39 ${ }^{\bullet \bullet}$ ]. This indicates their usefulness in analyzing intracellular transport, which is usually hard to uncover using classical tools.

\section{Click-chemistry of transport substrates}

In animal models, the problem of bulky fluorescent tags interfering with binding to transporter (or receptor) proteins has been partially solved by 'click chemistry' [68]. This technique triggers the selective, covalent connection between a molecule of interest and a detection tag in situ (Figure 2). A variety of labeling tags can be used then for microscopy or analytics.

To our knowledge only one study reported on the distribution of a mobile substrate using this technology in plants: the azido derivative of indole-3-propionic acid (IPA, an active auxin), IPA- $\mathrm{N}_{3}$, was used as an auxin tracer and provided some evidence of the presence of auxin binding sites in the apoplast of elongating cells $\left[69^{\bullet \bullet}\right]$. IPA-N ${ }_{3}$ was detected mainly in the outer cell layers of the root tip and does thus not fully reflect the auxin accumulation sites. This seems to be less a penetration but a fixation problem [69 ${ }^{\bullet \bullet}$. However, these technical issues will be overcome and as such 'click chemistry' might soon be the method of choice despite the fact that it requires a fixation step preventing in vivo imaging.

\section{Imaging of radiolabeled substrates}

Radio-autographic analysis of the distribution of transport has a long tradition in plants (e.g. [70]). Recently, polar auxin transport of Arabidopsis stem segments was visualized by detecting ${ }^{14} \mathrm{C}$-IAA with a double-sided silicon strip detector [71]. In recent years, the micro-autoradiography method (MAR) has been established to visualize the distribution of ${ }^{109} \mathrm{Cd}$ and ${ }^{33} \mathrm{P}$ within sections of rice 
tissues [72]. Currently, only fixed material can be used, preventing any dynamic information about substrate distributions. As ${ }^{14} \mathrm{C}$ (and ${ }^{3} \mathrm{H}$ ) emit beta particles at very low energy, most transport substrates could be labelled with suitable isotopes for autoradiography, which would expand the application properties of MAR (Figure 2; [72]).

\section{Immunolocalization of transport substrates}

ABA [73,74], IAA [22] and CK [75] have been visualized in different plant species by whole-mount immunolocalization using polyclonal and monoclonal antisera (Figure 2; [76]). Despite requiring of fixation, some of these antisera have become successful tools for the in situ localization of local maxima [75,77] or the translocation of hormones in plants [78-82]. Anti-IAA antibody signals were reported to recapitulate signals found with the $D R 5$ reporter in the mature and lateral root $[77,79]$. However, a part of these publications have been heavily debated with respect to their interpretation and technical quality [83].

\section{Modeling of transmembrane transport over tissues}

Early auxin transport models, called flux-based models, were inspired by Tsvi Sachs in the late 1960s and hypothesized that the flux of auxin through cell membranes reinforces itself $[84,85]$. The integration of experimentally determined patterns of transporter localization into simulations confirmed this in Arabidopsis [86-88,89 ${ }^{\circ}$ ]. Gradient-based models were introduced [90,91], provided support for the assumed roles of auxin maxima in shoot development (for an excellent review, see Ref. [92]).

The primary motivation of most of these studies was to predict the movement of a transported substrate (here: auxin; Figure 3) within a developing tissue. In this regard, the development of the OnGuard platform for modeling transport processes in stomata has proven successful in uncovering previously unexpected features of guard cell physiology [93]. However, today's interest lies more in testing if a hypothesized role for a substrate can be supported by in silico data [94]. A recent study employing data-driven modeling of intracellular auxin fluxes between the ER or cytoplasm and the nucleus, respectively, indicated that the ER has a dominant role in controlling nuclear auxin uptake [39 ${ }^{\bullet \bullet}$. This and other approaches argue that computer models can provide (or even go beyond) a 'proof of principle'. However, any conclusions-based on human-made, and as such subjective, algorithms will always require an experimental validation.

\section{Conclusions and perspectives}

Recently, the plant transport field has made a major conceptual shift away from a single transporter analysis toward a more integrative transporter approach, aimed at exploring transporter networks in order to understand their interplay and their incorporation into plant physiology. This progress has been made possible by the development of a series of techniques that allow visualization of local concentrations and movements of substrates in plant tissues. While early quantitative methods (like radiolabeled substrates, micro-electrodes and cell-type specific analyses of transport substrates) provide temporal resolution, visualization of transport by means of chemical indicators, fluorescent analogs and especially reporters and sensors provides good spatial information with reasonable resolution for many substrates. In that respect, doubting Thomas was right: seeing is better than believing.

Most tools have their individual advantages and limitations (see Figure 2). Some allow only for (semi)-quantitative analyses with high spatial but only low temporal resolution (such as reporters and sensors), while some indicators, sensors or fluorescent analogs were found to interfere with plant physiology by high substrate binding affinities or by competing with endogenous signaling $[24,32,57]$. However, these kinds of problems may to a certain degree be overcome by using non-plant substrate binding domains [95].

As usual, new technology and insight provides us with new challenges. For example, the transfer of sensors from single cell approaches to the plant level has been difficult due to the wide affinity/sensitivity range (nM$\mathrm{mM}$ ) that is required for some substrates. A solution might be the co-expression of spectrally non-overlapping, intensiometric sensors with different affinity ranges. Further, in contrast to intercellular transport, transmembrane transport between subcellular compartments has proven difficult to measure directly. In that respect, a directed targeting of sensors to individual subdomains of interest as shown recently [54 $4^{\bullet \bullet}$ ] and design of selective permeable fluorescent dyes [39 $\left.{ }^{\bullet \bullet}\right]$ will be helpful.

Another issue is the inadequate separation of transport from signaling/biosynthesis by some imaging tools, like reporters or sensors. In that respect it appears as if we have not yet fully used the potential of fluorescent transport substrates or click chemistry. In the future, structure-activity design will allow us to predict fluorophore positions and linker length $[63,64]$ in order to direct uptake, stability and distribution of fluorescent substrates [96].

\section{Acknowledgements}

The author would like to thank to Martin di Donato and Aurélien Bailly for discussion and comments. The constructive input of reviewers and editors is highly appreciated. Work in the geislerLab is currently funded by the Swiss National Funds (project 31003A_165877/1) and the European Space

Association (CORA-GBF project LIRAT). 


\section{References and recommended reading}

Papers of particular interest, published within the period of review, have been highlighted as

- of special interest

$\bullet$ of outstanding interest

1. Chen LQ, Cheung LS, Feng L, Tanner W, Frommer WB: Transport of sugars. Annu Rev Biochem 2015, 84:865-894.

2. Tanner W, Caspari T: Membrane transport carriers. Annu Rev Plant Physiol Plant Mol Biol 1996, 47:595-626.

3. Park J, Lee Y, Martinoia E, Geisler M: Plant hormone transporters: what we know and what we would like to know. BMC Biol 2017, 15:93.

4. Kang J, Lee Y, Sakakibara H, Martinoia E: Cytokinin transporters: GO and STOP in signaling. Trends Plant Sci 2017, 22:455-461.

5. Borghi L, Kang J, Ko D, Lee Y, Martinoia E: The role of ABCG-type ABC transporters in phytohormone transport. Biochem SoC Trans 2015, 43:924-930.

6. Geisler M, Wang B, Zhu J: Auxin transport during root gravitropism: transporters and techniques. Plant Biol (Stuttg) 2014, 16(Suppl. 1):50-57.

7. Yoshinari A, Takano J: Insights into the mechanisms underlying boron homeostasis in plants. Front Plant Sci 2017, 8:1951.

8. Naramoto S: Polar transport in plants mediated by membrane transporters: focus on mechanisms of polar auxin transport. Curr Opin Plant Biol 2017, 40:8-14.

9. Kang J, Park J, Choi H, Burla B, Kretzschmar T, Lee Y, Martinoia E: Plant ABC transporters. Arabidopsis Book 2011, 9e0153.

10. Adamowski M, Friml J: PIN-dependent auxin transport: action, regulation, and evolution. Plant Cell 2015, 27:20-32.

11. Grones P, Friml J: Auxin transporters and binding proteins at a glance. J Cell Sci 2015, 128:1-7.

12. Geisler M, Aryal B, di Donato M, Hao P: A critical view on ABC transporters and their interacting partners in auxin transport. Plant Cell Physiol 2017, 58:1601-1614.

13. Ast C, De Michele R, Kumke MU, Frommer WB: Singlefluorophore membrane transport activity sensors with dualemission read-out. eLife 2015, 4e07113.

14. De Michele R, Ast C, Loque D, $\mathrm{Ho} \mathrm{CH}$, Andrade S, Lanquar V, Grossmann G, Gehne S, Kumke MU, Frommer WB: Fluorescent sensors reporting the activity of ammonium transceptors in live cells. eLife 2013, 2e00800.

15. $\mathrm{Ho} \mathrm{CH}$, Frommer WB: Fluorescent sensors for activity and regulation of the nitrate transceptor CHL1/NRT1.1 and oligopeptide transporters. eLife 2014, 3e01917.

16. Aryal B, Laurent $C$, Geisler M: Learning from each other: $A B C$ transporter regulation by protein phosphorylation in plant and mammalian systems. Biochem Soc Trans 2015, 43:966-974.

17. Zourelidou M, Absmanner B, Weller B, Barbosa IC, Willige BC, Fastner A, Streit V, Port SA, Colcombet J, de la Fuente van Bentem $S$ et al:: Auxin efflux by PIN-FORMED proteins is activated by two different protein kinases, D6 PROTEIN KINASE and PINOID. eLife 2014e02860.

18. Christie JM, Yang H, Richter GL, Sullivan S, Thomson CE, Lin J, Titapiwatanakun B, Ennis M, Kaiserli E, Lee OR et al.: Phot1 inhibition of ABCB19 primes lateral auxin fluxes in the shoot apex required for phototropism. PLoS Biol 2011, 9e1001076.

19. Henrichs S, Wang B, Fukao Y, Zhu J, Charrier L, Bailly A, Oehring SC, Linnert M, Weiwad M, Endler A et al.: Regulation of ABCB1/PGP1-catalysed auxin transport by linker phosphorylation. EMBO J 2012, 31:2965-2980.

20. Armengot $L$, Marques-Bueno MM, Jaillais $Y$ : Regulation of polar auxin transport by protein and lipid kinases. J Exp Bot 2016, 67:4015-4037.
21. Zhang Q, Huang $\mathrm{H}$, Zhang L, Wu R, Chung $\mathrm{Cl}$, Zhang $\mathrm{SQ}$, Torra J, -• Schepis A, Coughlin SR, Kornberg TB et al.: Visualizing dynamics of cell signaling in vivo with a phase separation-based kinase reporter. Mol Cell 2018, 69:334-346 e334.

The SPARK-based protein kinase A reporter revealed oscillatory dynamics of PKA activities upon G protein-coupled receptor activation inDrosophila but has not yet been adopted to plant systems.

22. Parizkova B, Pernisova M, Novak O: what has been seen cannot be unseen-detecting auxin in vivo. Int J Mol Sci 2017, 18.

23. Jones AM, Grossmann G, Danielson JA, Sosso D, Chen LQ, $\mathrm{Ho} \mathrm{CH}$, Frommer WB: In vivo biochemistry: applications for small molecule biosensors in plant biology. Curr Opin Plant Biol 2013, 16:389-395.

24. Kanchiswamy CN, Malnoy M, Occhipinti A, Maffei ME: Calcium imaging perspectives in plants. Int J Mol Sci 2014, 15:38423859.

25. Braun FJ, Hegemann P: Direct measurement of cytosolic calcium and $\mathrm{pH}$ in living Chlamydomonas reinhardtii cells. Eur J Cell Biol 1999, 78:199-208.

26. Plieth C: Plant calcium signaling and monitoring: pros and cons and recent experimental approaches. Protoplasma 2001, 218:1-23.

27. Uslu VV, Grossmann G: The biosensor toolbox for plant developmental biology. Curr Opin Plant Biol 2016, 29:138-147.

28. Gjetting SK, Schulz A, Fuglsang AT: Perspectives for using genetically encoded fluorescent biosensors in plants. Front Plant Sci 2013, 4:234.

29. Lemke EA, Schultz C: Principles for designing fluorescent sensors and reporters. Nat Chem Biol 2011, 7:480-483.

30. Walia A, Waadt R, Jones AM: Genetically encoded biosensors in plants: pathways to discovery. Annu Rev Plant Biol 2018, 69:497-524.

31. Grossmann G, Krebs M, Maizel A, Stahl Y, Vermeer JEM, Ott T: Green light for quantitative live-cell imaging in plants. $J$ Cell Sci 2018, 131.

32. Waadt R, Hsu PK, Schroeder Jl: Abscisic acid and other plant hormones: methods to visualize distribution and signaling. Bioessays 2015, 37:1338-1349.

33. Ulmasov T, Murfett J, Hagen G, Guilfoyle TJ: Aux/IAA proteins repress expression of reporter genes containing natural and highly active synthetic auxin response elements. Plant Cell 1997, 9:1963-1971.

34. Hayashi K, Nakamura S, Fukunaga S, Nishimura T, Jenness MK,

- $\quad$ Murphy AS, Motose H, Nozaki H, Furutani M, Aoyama T: Auxin transport sites are visualized in planta using fluorescent auxin analogs. Proc Natl Acad Sci U S A 2014, 111:11557-11562.

Innovative design of fluorescent auxin analogs to be actively transported but to be inactive for auxin signaling avoiding unwanted auxin transporter expression and location. Used to dissect cytoplasmic and ER delivery of nuclear auxin concentrations [45].

35. Sokolowska K, Kizinska J, Szewczuk Z, Banasiak A: Auxin conjugated to fluorescent dyes - a tool for the analysis of auxin transport pathways. Plant Biol (Stuttg) 2014, 16:866-877.

36. Brunoud G, Wells DM, Oliva M, Larrieu A, Mirabet V, Burrow AH, Beeckman T, Kepinski S, Traas J, Bennett MJ et al.: A novel sensor to map auxin response and distribution at high spatiotemporal resolution. Nature 2012, 482:103-106.

37. Liao CY, Smet W, Brunoud G, Yoshida S, Vernoux T, Weijers D:

- Reporters for sensitive and quantitative measurement of auxin response. Nat Methods 2015, 12:207-210 202-210.

A set of auxin reporters that allow sensitive and semi-quantitative detection of auxin signaling and responses in plants.DR5V2 offers by dual-color imaging an extended range of auxin responses, while, R2D2 allows for a ratiometric analysis of auxin.

38. Wend S, Dal Bosco C, Kampf MM, Ren F, Palme K, Weber W, Dovzhenko A, Zurbriggen MD: A quantitative ratiometric sensor for time-resolved analysis of auxin dynamics. Sci Rep 2013, 3:2052. 
39. Middleton AM, Dal Bosco C Chlap P Bensch R, Harz H, Ren F, - Bergmann S, Wend S, Weber W, Hayashi KI et al.: Data-driven modeling of intracellular auxin fluxes indicates a dominant role of the ER in controlling nuclear auxin uptake. Cell Rep 2018, 22:3044-3057.

Elegant study that by employing a data-driven modeling of intracellular auxin fluxes between the ER or cytoplasm and the nucleus, respectively, and a fluorescent auxin analog with restricted nuclear passage indicated that the ER has a dominant role in controlling nuclear auxin uptake.

40. Lofke C, Zwiewka M, Heilmann I, Van Montagu MC, Teichmann T, Friml J: Asymmetric gibberellin signaling regulates vacuolar trafficking of PIN auxin transporters during root gravitropism. Proc Natl Acad Sci U S A 2013, 110:3627-3632.

41. Larrieu A, Champion A, Legrand J, Lavenus J, Mast D, Brunoud G, Oh J, Guyomarc'h S, Pizot M, Farmer EE et al.: A fluorescent hormone biosensor reveals the dynamics of jasmonate signalling in plants. Nat Commun 2015, 6:6043.

42. Samodelov SL, Beyer HM, Guo X, Augustin M, Jia KP, Baz L, Ebenhoh O, Beyer P, Weber W, Al-Babili S et al.: StrigoQuant: a genetically encoded biosensor for quantifying strigolactone activity and specificity. Sci Adv 2016, 2e1601266.

43. Okumoto S, Jones A, Frommer WB: Quantitative imaging with fluorescent biosensors. Annu Rev Plant Biol 2012, 63:663-706.

44. Zhu X, Feng Y, Liang G, Liu N, Zhu JK: Aequorin-based luminescence imaging reveals stimulus- and tissue-specific Ca2+ dynamics in Arabidopsis plants. Mol Plant 2013, 6:444455.

45. Hillearya R, Choib WG, Kimb SH, Limb SH, Gilroy S: Sense and sensibility: the use of fluorescent protein-based genetically encoded biosensors in plants. Curr Opin Plant Biol 2018, 46:3238 http://dx.doi.org/10.1016/j.pbi.2018.07.004.

46. Monshausen GB, Messerli MA, Gilroy S: Imaging of the Yellow Cameleon 3.6 indicator reveals that elevations in cytosolic $\mathrm{Ca} 2$ + follow oscillating increases in growth in root hairs of Arabidopsis. Plant Physiol 2008, 147:1690-1698.

47. Choi WG, Gilroy S: Plant biologists FRET over stress. eLife 2014 $3 \mathrm{e} 02763$.

48. Choi WG, Toyota M, Kim SH, Hilleary R, Gilroy S: Salt stressinduced $\mathrm{Ca} 2+$ waves are associated with rapid, long-distance root-to-shoot signaling in plants. Proc Natl Acad Sci U S A 2014, 111:6497-6502.

49. Monshausen GB, Miller ND, Murphy AS, Gilroy S: Dynamics of auxin-dependent $\mathrm{Ca} 2+$ and $\mathrm{pH}$ signaling in root growth revealed by integrating high-resolution imaging with automated computer vision-based analysis. Plant $J \mathbf{2 0 1 1 ,}$ 65:309-318.

50. Keinath NF, Waadt R, Brugman R, Schroeder JI, Grossmann G,

-• Schumacher K, Krebs M: Live cell imaging with R-GEC01 sheds light on flg22- and chitin-induced transient $[\mathrm{Ca}(2+)] c y t$ patterns in arabidopsis. Mol Plant 2015, 8:1188-1200.

The direct comparison between the ratiometric and intensiometric calcium sensors, YC3.6 and R-GECO, revealed a higher dynamic range for $\mathrm{R}-\mathrm{GECO}$ in response to elicitors of the innate immune response.

51. Dindas J, Scherzer S, Roelfsema MRG, von Meyer K, Muller HM,

-• Al-Rasheid KAS, Palme K, Dietrich P, Becker D, Bennett MJ et al.: AUX1-mediated root hair auxin influx governs SCF(TIR1/AFB)type $\mathrm{Ca}(2+)$ signaling. Nat Commun 2018, 9:1174.

The calcium sensor, R-GECO1, was used to image auxin-induced calcium gradients in root-hair tips but also long-distance calcium waves between root cells.

52. Miesenbock G, De Angelis DA, Rothman JE: Visualizing secretion and synaptic transmission with $\mathrm{pH}$-sensitive green fluorescent proteins. Nature 1998, 394:192-195.

53. Gjetting KS, Ytting CK, Schulz A, Fuglsang AT: Live imaging of - intra- and extracellular $\mathrm{pH}$ in plants using pHusion, a novel genetically encoded biosensor. J Exp Bot 2012, 63:3207-3218.

The $\mathrm{pH}$ sensor, pHusion, allowed for a ratiometric quantification of cytoplasmic and especially apoplastic $\mathrm{pH}$, demonstrated by the immediate alkalinization of the subepidermal apoplast upon external auxin treatment.
54. Luo $Y$, Scholl $S$, Doering A, Zhang $Y$, Irani NG, Rubbo SD,

-• Neumetzler L, Krishnamoorthy P, Van Houtte I, Mylle E et al.: VATPase activity in the TGN/EE is required for exocytosis and recycling in Arabidopsis. Nat Plants 2015, 1:15094.

Usage of the ratiometric sensor, pHusion, for measuring $\mathrm{pH}$ inside and outside of TGN/early endosomes unveiled the importance of acidification for secretion and recycling.

55. Chen LQ, Hou BH, Lalonde S, Takanaga H, Hartung ML, Qu XQ, Guo WJ, Kim JG, Underwood W, Chaudhuri B et al.: Sugar transporters for intercellular exchange and nutrition of pathogens. Nature 2010, 468:527-532

56. Imamura $\mathrm{H}$, Nhat KP, Togawa $\mathrm{H}$, Saito $\mathrm{K}$, lino $\mathrm{R}$, Kato-Yamada $\mathrm{Y}$, Nagai T, Noji H: Visualization of ATP levels inside single living cells with fluorescence resonance energy transfer-based genetically encoded indicators. Proc Natl Acad Sci U S A 2009 106:15651-15656

57. De Col V, Fuchs P, Nietzel T, Elsasser M, Voon CP, Candeo A Seeliger I, Fricker MD, Grefen C, Moller IM et al.: ATP sensing in living plant cells reveals tissue gradients and stress dynamics of energy physiology. eLife 2017, 6 .

58. Okumoto S, Versaw W: Genetically encoded sensors for monitoring the transport and concentration of nitrogencontaining and phosphorus-containing molecules in plants. Curr Opin Plant Biol 2017, 39:129-135.

59. Jones AM, Danielson JA, Manojkumar SN, Lanquar V,

- Grossmann G, Frommer WB: Abscisic acid dynamics in roots detected with genetically encoded FRET sensors. eLife 2014 $3 \mathrm{e} 01741$.

This study as well as $\left[59^{\circ}\right]$ developed the first phytohormone (ABA) sensor.

60. Waadt R, Hitomi K, Nishimura N, Hitomi C, Adams SR, Getzoff ED,

- $\quad$ Schroeder JI: FRET-based reporters for the direct visualization of abscisic acid concentration changes and distribution in Arabidopsis. elife 2014, 3e01739.

This study as well as $\left[5^{\circ}\right]$ developed the first phytohormone (ABA) sensor

61. Rizza A, Walia A, Lanquar V, Frommer WB, Jones AM: In vivo gibberellin gradients visualized in rapidly elongating tissues. Nat Plants 2017, 3:803-813

62. Irani NG, Di Rubbo S, Mylle E, Van den Begin J, Schneider-Pizon J, Hnilikova J, Sisa M, Buyst D, Vilarrasa-Blasi J, Szatmari AM et al.: Fluorescent castasterone reveals BRI1 signaling from the plasma membrane. Nat Chem Biol 2012, 8:583-589.

63. Shani E, Weinstain R, Zhang Y, Castillejo C, Kaiserli E, Chory J, Tsien RY, Estelle M: Gibberellins accumulate in the elongating endodermal cells of Arabidopsis root. Proc Natl Acad Sci U S A 2013, 110:4834-4839.

64. Bieleszova K, Parizkova B, Kubes M, Husickova A, Kubala M, Ma Q, Sedlarova M, Robert S, Dolezal K, Strnad M et al.: New fluorescently labeled auxins exhibit promising anti-auxin activity. N Biotechnol 2018. Jun 25. pii: S1871-6784(17)30572-1. doi: 10.1016/j.nbt.2018.06.003. [Epub ahead of print]

65. Gao Y, Yu Y, Hu X, Cao Y, Wu J: Imaging of jasmonic acid binding sites in tissue. Anal Biochem 2013, 440:205-211.

66. Rasmussen A, Heugebaert T, Matthys C, Van Deun R, Boyer FD, Goormachtig S, Stevens C, Geelen D: A fluorescent alternative to the synthetic strigolactone GR24. Mol Plant 2013, 6:100-112.

67. Kameoka H, Kyozuka J: Spatial regulation of strigolactone function. J Exp Bot 2018, 69(9 April):2255-2264 http://dx.doi.org/ $10.1093 / \mathrm{jxb} / \mathrm{erx} 434$.

68. Horisawa K: Specific and quantitative labeling of biomolecules using click chemistry. Front Physiol 2014, 5:457.

69. Mravec J, Kracun SK, Zemlyanskaya E, Rydahl MG, Guo X,

-. Picmanova M, Sorensen KK, Ruzicka K, Willats WGT: Click chemistry-based tracking reveals putative cell wall-located auxin binding sites in expanding cells. Sci Rep 2017, 7:15988.

First study using 'click chemistry' in order image a hormone (auxin) tracer in plants providing evidence for the presence of auxin binding sites in the apoplast of elongating cells. 
70. Sabnis DD, Hirshberg G, Jacobs WP: Radioautographic analysis of the distribution of label from $\mathrm{h}$-indoleacetic acid supplied to isolated coleus internodes. Plant Physiol 1969, 44:27-36.

71. Boot KJ, Hille SC, Libbenga KR, Peletier LA, van Spronsen PC, van Duijn B, Offringa R: Modelling the dynamics of polar auxin transport in inflorescence stems of Arabidopsis thaliana. J Exp Bot 2016, 67:649-666.

72. Hirose A, Kobayashi NI, Tanoi K, Nakanishi TM: A microautoradiographic method for fresh-frozen sections to reveal the distribution of radionuclides at the cellular level in plants. Plant Cell Physiol 2014, 55:1194-1202.

73. Pastor ACN, Alegre L: Immunolocalization of abscisic acid by monoclonal antibodies in Lavandula stoechas L. leaves. Plant Growth Regul 1995, 16:287-292.

74. Sharipova G, Veselov D, Kudoyarova G, Fricke W, Dodd IC, Katsuhara M, Furuichi T, Ivanov I, Veselov S: Exogenous application of abscisic acid (ABA) increases root and cell hydraulic conductivity and abundance of some aquaporin isoforms in the ABA-deficient barley mutant Az34. Ann Bot 2016, 118(4):777-785.

75. Casanova E, Valdes AE, Fernandez B, Moysset L, Trillas MI: Levels and immunolocalization of endogenous cytokinins in thidiazuron-induced shoot organogenesis in carnation. J Plant Physiol 2004, 161:95-104.

76. Pasternak T, Tietz O, Rapp K, Begheldo M, Nitschke R, Ruperti B, Palme K: Protocol: an improved and universal procedure for whole-mount immunolocalization in plants. Plant Methods 2015, 11:50

77. Benkova E, Michniewicz M, Sauer M, Teichmann T, Seifertova D, Jurgens G, Friml J: Local, efflux-dependent auxin gradients as a common module for plant organ formation. Cell 2003, 115:591602.

78. Bouchard R, Bailly A, Blakeslee JJ, Oehring SC, Vincenzetti V, Lee OR, Paponov I, Palme K, Mancuso S, Murphy AS et al.: Immunophilin-like TWISTED DWARF1 modulates auxin efflux activities of Arabidopsis P-glycoproteins. J Biol Chem 2006, 281:30603-30612.

79. Krouk G, Lacombe B, Bielach A, Perrine-Walker F, Malinska K, Mounier E, Hoyerova K, Tillard P, Leon S, Ljung K et al.: Nitrateregulated auxin transport by NRT1.1 defines a mechanism for nutrient sensing in plants. Dev Cell 2010, 18:927-937.

80. Nishimura T, Toyooka K, Sato M, Matsumoto S, Lucas MM, Strnad M, Baluska F, Koshiba T: Immunohistochemical observation of indole-3-acetic acid at the IAA synthetic maize coleoptile tips. Plant Signal Behav 2011, 6:2013-2022.

81. Mettbach U, Strnad M, Mancuso S, Baluska F: Immunogold-EM analysis reveal brefeldin a-sensitive clusters of auxin in Arabidopsis root apex cells. Commun Integr Biol 2017, 10e1327105.

82. Schlicht M, Strnad M, Scanlon MJ, Mancuso S, Hochholdinger F, Palme K, Volkmann D, Menzel D, Baluka F: Auxin immunolocalization implicates vesicular neurotransmitterlike mode of polar auxin transport in root apices. Plant Signal Behav 2006, 1:122-133.

83. Robinson DG, Hawes C, Hillmer S, Jurgens G, Schwechheimer C, Stierhof YD, Viotti C: Auxin and vesicle traffic. Plant Physiol 2018, 176:1884-1888.
84. Sachs T: Polarity and the induction of organized vascular tissues. Ann. Bot. (Lond) 1969, 33:263-272.

85. Bennett $\mathrm{T}$, Hines $\mathrm{G}$, Leyser $\mathrm{O}$ : Canalization: what the flux? Trends Genet 2014, 30:41-48.

86. de Reuille PB, Bohn-Courseau I, Ljung K, Morin H, Carraro N, Godin C, Traas J: Computer simulations reveal properties of the cell-cell signaling network at the shoot apex in Arabidopsis. Proc Natl Acad Sci U S A 2006, 103:1627-1632.

87. Grieneisen VA, Xu J, Maree AF, Hogeweg P, Scheres B: Auxin transport is sufficient to generate a maximum and gradient guiding root growth. Nature 2007, 449:1008-1013.

88. Peret B, Middleton AM, French AP, Larrieu A, Bishopp A, Njo M Wells DM, Porco S, Mellor N, Band LR et al.: Sequential induction of auxin efflux and influx carriers regulates lateral root emergence. Mol Syst Biol 2013, 9:699.

89. Band LR, Wells DM, Fozard JA, Ghetiu T, French AP, Pound MP

- Wilson MH, Yu L, Li W, Hijazi HI et al.: Systems analysis of auxin transport in the Arabidopsis root apex. Plant Cell 2014, 26:862875.

An auxin transport model-based on actual root cell geometries and subcellular localizations of auxin carriers was tested using DII-VENUSderived data. This study revealed that AUX1/LAX influx carriers are also required beside efflux carriers to create the pattern of auxin distribution at the root tip.

90. Smith RS, Guyomarc'h S, Mandel T, Reinhardt D, Kuhlemeier C, Prusinkiewicz P: A plausible model of phyllotaxis. Proc Natl Acad Sci U S A 2006, 103:1301-1306.

91. Jonsson H, Heisler MG, Shapiro BE, Meyerowitz EM, Mjolsness E: An auxin-driven polarized transport model for phyllotaxis. Proc Natl Acad Sci U S A 2006, 103:1633-1638.

92. Voss U, Bishopp A, Farcot E, Bennett MJ: Modelling hormonal response and development. Trends Plant Sci 2014, 19:311-319.

93. Hills A, Chen ZH, Amtmann A, Blatt MR, Lew VL: OnGuard, a computational platform for quantitative kinetic modeling of guard cell physiology. Plant Physiol 2012, 159:1026-1042.

94. Kramer EM: Computer models of auxin transport: a review and commentary. J Exp Bot 2008, 59:45-53.

95. Heim N, Garaschuk O, Friedrich MW, Mank M, Milos RI, Kovalchuk Y, Konnerth A, Griesbeck O: Improved calcium imaging in transgenic mice expressing a troponin C-based biosensor. Nat Methods 2007, 4:127-129.

96. Lace B, Prandi C: Shaping small bioactive molecules to untangle their biological function: a focus on fluorescent plant hormones. Mol Plant 2016, 9:1099-1118.

97. Wang B, Bailly A, Zwiewka M, Henrichs S, Azzarello E, Mancuso S Maeshima M, Friml J, Schulz A, Geisler M: Arabidopsis TWISTED DWARF1 functionally interacts with auxin exporter ABCB1 on the root plasma membrane. Plant Cell 2013, 25:202-214.

98. Petersson SV, Johansson Al, Kowalczyk M, Makoveychuk A, Wang JY, Moritz T, Grebe M, Benfey PN, Sandberg G, Ljung K: An auxin gradient and maximum in the arabidopsis root apex shown by high-resolution cell-specific analysis of iaa distribution and synthesis. Plant Cell 2009, 21(6):1659-1668. 